\title{
Article \\ Selective and Efficient Arsenic Recovery from Water through Quaternary Amino-Functionalized Silica
}

\author{
Oscar Valdés ${ }^{1}{ }^{(\mathbb{D}}$, Adolfo Marican ${ }^{2}$, Yaneris Mirabal-Gallardo ${ }^{3}$ and Leonardo S. Santos ${ }^{4, *}$ \\ 1 Vicerrectoría de Investigación y Postgrado, Universidad Católica del Maule, 3460000 Talca, Chile; \\ ovaldes@ucm.cl \\ 2 Instituto de Química de Recursos Naturales, Universidad de Talca, 3460000 Talca, Chile; amarican@utalca.cl \\ 3 Instituto de Ciencias Químicas Aplicadas, Facultad de Ingeniería en Construcción, \\ Universidad Autónoma de Chile, 3460000 Talca, Chile; yaneris.mirabal@uautonoma.cl \\ 4 Laboratory of Asymmetric Synthesis, Instituto de Química de Recursos Naturales, Universidad de Talca, \\ 3460000 Talca, Chile \\ * Correspondence: lssantos@utalca.cl; Tel.: +56-71-2201575
}

Received: 9 May 2018; Accepted: 30 May 2018; Published: 7 June 2018

\begin{abstract}
The free-radical graft polymerization of acryloxyethyl-trimethylammonium chloride onto commercial silica particles was studied experimentally for extraction of arsenic ions from water. Two steps were used to graft acryloxyethyl-trimethylammonium chloride (Q) onto the surface of nanosilica: anchoring vinyltrimethoxysilane (VTMSO) onto the surface of silica to modify it with double bonds and then grafting $Q$ onto the surface of silica with potassium persulfate as an initiator. The products were characterized by Fourier-transform infrared (FT-IR), the thermogravimetric analysis (TGA), scanning electron microscopy (SEM), ${ }^{13} \mathrm{C},{ }^{29} \mathrm{Si}$ nuclear magnetic resonance (NMR), and $X$-ray powder diffraction (XRD). The results showed that it is easy to graft $Q$ onto the surface of silica under radical polimerization. The morphology analysis of silica and modified silica indicated that the silica decreased the size scale after modification. Q/VTMSO-SiO ${ }_{2}$ was tested for its ability to remove arsenic from drinking water. The results show that the new silica hybrid particles efficiently remove all arsenate ions. In addition, $\mathrm{Q} / \mathrm{VTMSO}-\mathrm{SiO}_{2}$ showed better sorption capacities for other metal ions (such as copper, zinc, chromium, uranium, vanadium, and lead) than a commercial water filter.
\end{abstract}

Keywords: quaternary ammonium; arsenic; vinyltrimethoxysilane; graft polymerization; silica

\section{Introduction}

Arsenic contamination of tap water is reported in many undeveloped countries and is considered a primary environmental health hazard throughout the world. Arsenic is an element found in the Earth's crust and is mobilized through natural processes. As a consequence of these anthropogenic activities, arsenic enters the water cycle [1]. However, agricultural and industrial practices such as mining activities, combustion of fossil fuels, use of arsenic pesticides, electronics production waste, crop desiccants, runoff from glass production, and use of arsenic additives to livestock feed can lead to an increase in the concentration of arsenic in water sources [1]. For these reasons, the greatest risk of human contamination by arsenic is probably due to the ingestion of polluted water.

It is known that small doses of arsenic in the human body cause or aggravate many diseases such as cardiovascular, pulmonary, immunological, neurological, peripheral vascular, and endocrine and different types of cancer (e.g., lung, bladder, skin, prostate, kidney, etc.) [2,3]. With this in mind, the World Health Organization suggests $0.05 \mathrm{ppm}$ as the maximum level of arsenic in drinking water [4]. This element is naturally found in water in two oxidation states, arsenite $\left(\mathrm{AsO}_{3}{ }^{3-}\right)$ and 
arsenate $\left(\mathrm{AsO}_{4}{ }^{3-}\right)$. The presence of each oxidation state depends on the redox potential, $\mathrm{pH}$ condition, other ions, and microbial activity. Arsenate species are less toxic than arsenite, which is more widespread in aerobic surface waters. On the other hand, trivalent arsenites predominate in moderately reduced anaerobic environments such as groundwater [5]. Many countries like the USA, China, Chile, Bangladesh, Argentina, Poland, Mexico, Taiwan, Canada, Hungary, New Zealand, Japan, and India have recently reported cases of chronic exposure to high amounts of arsenic in water [1]. Therefore, arsenic in natural water is a worldwide dilemma that has not yet been resolved.

Several techniques have been developed to eliminate arsenic from aqueous solutions, including adsorption, oxidation, precipitation, electrocoagulation, membrane permeation, and biological methods, with far less attention paid to adsorption [6]. Low-cost adsorbents can be used for arsenic removal from drinking water and groundwater with high efficiency. Adsorption involves the use of granular materials for the selective elimination of arsenic from water with or without $\mathrm{pH}$ adjustment and spent media regeneration. Therefore, many adsorptive media have been used, for example activated alumina, ion exchange resin, elemental iron or iron compounds, organic polymers, chars, coal, red mud, blast furnace slag (BFS), kaolin clay, and silica sand, among others. Iron hydroxide or zero-valent irons are the most widely used [1]. There are many variables to select a proper sorbent media to remove arsenic from drinking water, such as: the range of arsenic concentrations, other elements and their concentrations, adsorbent dose, filtration of treated water, adjustment of $\mathrm{pH}$, post-treatment difficulties, handling of waste and, finally, proper operation and maintenance. The other contaminants found in tap water that could be occupying the active sites of the adsorbent are generating competition for the retention of the target pollutant, reducing treatment run times. For these reasons, adsorbent selection is a complex decision.

Sorbent technologies, which are successful in the laboratory, may fail in field conditions [1]. Additionally, these techniques generate mostly used adsorbents or collected residues polluted by arsenic species, and they must be properly treated as hazardous wastes. Therefore, the selection of the correct sorbent technologies for efficient arsenic removal from contaminated water is an essential issue regarding environmental remediation and human health.

Water-soluble polymers are a new type of purification technique for arsenic. Water-soluble polymers undergo interactions with solvent and other high- and low-molecular-weight species present in aqueous solutions $[7,8]$. There are different cationic polymers containing an exchanger quaternary ammonium group to remove arsenic species from aqueous media. These polymers have the following advantages: soluble in water with a high number of functional groups, exchange anions with arsenic species, and, thus, have higher efficiency. These polymers can be used with ultrafiltration membranes $[9,10]$. The problem with this technique is that these technologies need the combination of electrochemical oxidation and adsorption or ultrafiltration procedures, and therefore are not suitable for industrial applications.

To address this inconvenience and leverage the benefits previously mentioned, we propose a new organic-inorganic hybrid material design using a vinyltrimethoxysilane-acryloxyethyltrimethylammonium chloride polymer $\left(\mathrm{Q} / \mathrm{VTMSO}-\mathrm{SiO}_{2}\right)$ and ion-exchange properties for removing arsenate anions from water.

Finally, it is important to note that organic-inorganic hybrid materials have attracted significant attention [11-15] because of their potential applications in many surface-based technologies such as composite materials, biomaterials, adhesion and wetting, molecular recognition, microfluidics, chemical sensing, and organic synthesis [16-22]. In addition, this kind of material has excellent properties, such as mechanical properties, biodegradation and abrasion resistance, thermal stability, flame retardance, and gas barrier properties [23-26].

Presently, there are many approaches for modifying inorganic surfaces with polymers but the most frequently used is covalent attachment $[27,28]$. Specifically, three methods give the best results: the "grafting to" method [29,30], where the end-functionalized polymers react with an appropriate surface; the "grafting from" method [31,32], where polymer chains are grown 
from initiator-terminated self-assembled monolayers, and, finally, the "grafting onto" method [33], where surface copolymerization is through a covalently linked monomer.

In this article we report on the second type of approaches to covalently graft polymer chains on the surface of inorganic particles described previously. In particular, we prepared acrylic-functionalized silica particles and their copolymerization with acrylic monomer using radical polymerization for making an acrylic-silica hybrid composite. In addition, we focus on the chemical and structural characterization and the morphology. Moreover, the use of the acrylic monomer with a quaternary ammonium group significantly enhanced the ion-exchange properties of arsenate anions, as mentioned earlier.

\section{Experimental Section}

\subsection{Materials}

All chemical products were analytical grade. Silica $\left(\mathrm{SiO}_{2}\right)$ (Fluka, Santiago, Chile) with a particle size of $0.063-0.020 \mathrm{~mm}(70-230 \mathrm{mesh})$ and a mean pore size of $60 \AA$ was used as support. Hydrochloric acid (Fluka) and Vinyltrimethoxysilane (VTMSO, Sigma-Aldrich Chemical, Santiago, Chile) were used without purification. Toluene (Merck, Santiago, Chile) was distilled and dried with metallic sodium, which was then used as the solvent for the silylation process. Potassium persulfate $\left(\mathrm{K}_{2} \mathrm{~S}_{2} \mathrm{O}_{8}\right.$, Fluka) was employed as the initiator for acryloxyethyl-trimethylammonium chloride (Q, Sigma-Aldrich Chemical) free-radical polymerization. Pure Milli-Q water (Elga Labwater, High Wycombe, UK) was employed during the arsenic recovery experiments. The commercial polymer was obtained from a water filter purchased in a local market. We used normal drinking water for the metal affinity experiments between the filler from the purchased water filter and Q/VTMSO-SiO 2 .

\subsection{Silylation}

Initially, the silica particles were cleaned with $1 \% \mathrm{HCl}$ solution for $1 \mathrm{~h}$ at room temperature, followed by several rinses with water until it had a neutral $\mathrm{pH}$ to clean the surface. After that, particles were filtered and dried at $110^{\circ} \mathrm{C}$ in a vacuum oven overnight to remove excess surface water. Then, the hydroxylated particles were immersed in $7 \mathrm{mM}$ toluene solution of VTMSO at $30{ }^{\circ} \mathrm{C}$ under stirring for $18 \mathrm{~h}$ to form VTMSO-silylated particles. Subsequently, the silylated particles were washed with a large volume of toluene and methanol to remove the excess of VTMSO and dried at $80^{\circ} \mathrm{C}$ until a constant weight. The VTMSO-silylated particles were obtained as a white powder and the quantity of grafted VTMSO on the surface of the silica particles was calculated by TGA (TA Instruments, New Castle, DE, USA) using the following equation [34]:

$$
\text { Grafting density }\left(\frac{m o l}{m^{2}}\right)=\frac{\left(\frac{W_{1}}{100-W_{1}}\right) \times 100-W_{\mathrm{Si}}}{M S_{\mathrm{Spec}} \times 100} \times 10^{6},
$$

where $W_{1}$ is the weight loss from 110 to $700{ }^{\circ} \mathrm{C}$, corresponding to the decomposition of the VTMSO; $M(\mathrm{~g} / \mathrm{mol})$ is the molar mass of the degradable part of the grafted molecule $(105 \mathrm{~g} / \mathrm{mol})$; and $S_{\text {spec }}$ $\left(314 \mathrm{~m}^{2} / \mathrm{g}\right)$ and $W_{\mathrm{Si}}$ are the specific surface area and the weight loss of silica determined before grafting, respectively. The $S_{\text {spec }}$ were determined by nitrogen sorption isotherms with a standard BET method using a Tristar 3020 Micrometrics apparatus (Micromeritics, Norcross, GA, USA). Prior to the measurements, the silica particles were heated at $140{ }^{\circ} \mathrm{C}$ for $24 \mathrm{~h}$ under a vacuum.

\subsection{Graft Polymerization}

Free-radical graft polymerization of acryloxyethyl-trimethylammonium chloride $(\mathrm{Q})$ onto VTMSO-silylated particles was carried out in a necked flask using $0.01 \mathrm{M}$ of $\mathrm{K}_{2} \mathrm{~S}_{2} \mathrm{O}_{8}$ as initiator (Scheme 1). The initial monomer concentration (Q) was $80 \%$ of VTMSO-silylated particles weight using a predetermined volume of water. The reaction was performed under a nitrogen atmosphere at $60^{\circ} \mathrm{C}$, 
using magnetic stirring overnight. After the reaction time, the reaction mixture was filtered and washed with water to eliminate the excess of unreactive Q. Finally, the acryloxyethyl-trimethylammonium chloride on VTMSO-silylated particles $\left(\mathrm{Q} / \mathrm{VTMSO}-\mathrm{SiO}_{2}\right)$ was dried under a vacuum until constant weight was attained. The grafting percentage of modified silica was determined by thermogravimetric analyses. The percentage of acryloxyethyl-trimethylammonium chloride based on VTMSO-silylated particles was calculated by the following equation [35]:

$$
\text { Polymer grafting }(\%)=\frac{A}{B} \times 100,
$$

where $A$ is the weight of organic compounds grafted onto the VTMSO-silylated particles (mg), obtained from the TGA data; and $B$ is the weight of VTMSO-silylated particles (mg).

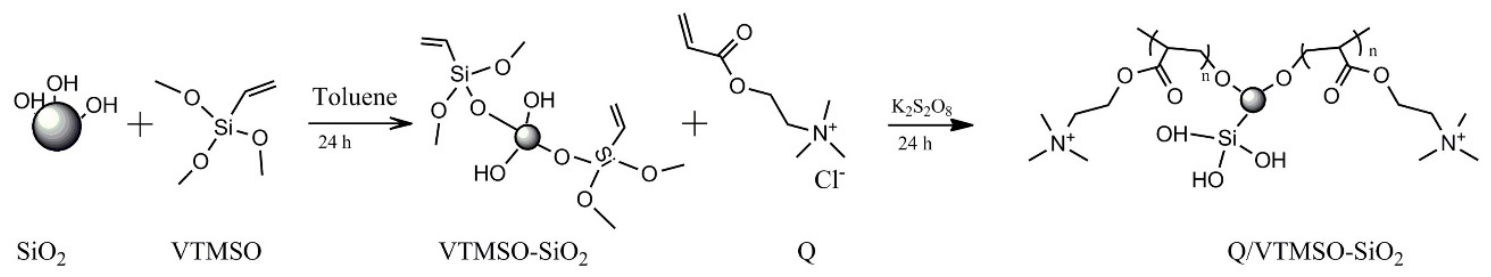

Scheme 1. Radical grafting procedures on silica with $Q$ investigated in this work.

\subsection{Characterization}

Fourier-transform infrared (FT-IR) spectrophotometer (Nicolet Nexus 470, Nicolet Instruments, Offenbach, Germany) was employed to obtain spectra of acryloxyethyl-trimethylammonium chloride on VTMSO-silylated particles (Q/VTMSO-SiO ${ }_{2}$ ). All spectrums were obtained in $\mathrm{KBr}$ pellets from an average of 32 scans with $4 \mathrm{~cm}^{-1}$ resolution within the $4000-400 \mathrm{~cm}^{-1}$ spectral interval. The Q/VTMSO-SiO ${ }_{2}$ was characterized by a comparison of the FT-IR spectra of the silica and VTMSO-silylated particles. Thermogravimetric analyses of the thermally treated samples were performed with a TA Instruments Q500 thermal gravimetric analyzer. The sample powders were heated in a nitrogen flow speed of $50 \mathrm{~mL} / \mathrm{min}$ from ambient temperature to $700{ }^{\circ} \mathrm{C}$ at a rate of $10{ }^{\circ} \mathrm{C} / \mathrm{min}$. Carbon-13 and Silicon-29 Nuclear Magnetic Resonance spectra for solid samples were obtained on a Varian INOVA 300 spectrometer (Varian, Inc., Palo Alto, CA, USA) equipped with a Cross Polarization-Magic Angle Spinning (CP/MAS) solid-state probe operating at resonance frequency of $74.5 \mathrm{MHz}$ and $5 \mathrm{KHz}$ for ${ }^{13} \mathrm{C}$ and ${ }^{29} \mathrm{Si}$, respectively. X-ray diffraction (XRD) was recorded on a Rigaku RIX 3100 spectrometer (Rigaku Corp., Tokyo, Japan) with copper anode as the source of X-rays at $\lambda=1.54 \AA$. The morphologies of $\mathrm{SiO}_{2}, \mathrm{VTMSO}-\mathrm{SiO}_{2}$ and $\mathrm{Q} / \mathrm{VTMSO}-\mathrm{SiO}_{2}$ were observed by a scanning electron microscope (JEOL JSM 5610LV, Tokyo, Japan) using a $20 \mathrm{kV}$ accelerating voltage.

\subsection{Metal Affinity Studies}

Solid Phase Extraction (SPE) cartridges were made with $5 \mathrm{~mL}$ polyethylene disposable syringes, using silanized glass wool as support for the polymers. $500 \mathrm{mg}$ of polymer was used per experiment. These filters were mounted on a Manifold Visiprep SPE vacuum system (Bellefonte, PA, USA) to achieve constant and reproducible flows. In the first stage, $1 \mathrm{~L}$ of arsenic model solution $\left(0.1 \mathrm{mg} \cdot \mathrm{L}^{-1}\right)$ was freshly prepared using Milli-Q water. Six aliquots of $160 \mathrm{~mL}$ of this solution were passed through the cartridge containing Q/VTMSO-SiO ${ }_{2}$ to determine its affinity by arsenic. In the second stage, arsenic spiked drinking water was used to evaluate the affinity of $\mathrm{Q} / \mathrm{VTMSO}-\mathrm{SiO}_{2}$ and commercial polymer in parallel. In this way, the retention capacity of the polymers by As was evaluated using an experimental design, considering the elution volume $(100,300$, and $500 \mathrm{~mL}$ ) through the filters, and the concentration of drinking water $\left(16.38,87.42\right.$, and $\left.409.2 \mu \mathrm{g} \cdot \mathrm{L}^{-1}\right)$. The values of these experimental variables were coded between -1 and 1 so that they had the same statistical weight. 
Finally, the determination of arsenic and other metals present in the drinking water, such as copper, zinc, chromium, uranium, vanadium and lead $(\mathrm{Cu}, \mathrm{Zn}, \mathrm{Cr}, \mathrm{U}, \mathrm{V}$, and $\mathrm{Pb})$ was carried using ICP-MS iCAP Q equipment (ThermoFisher Scientific, Bremen, Germany). The parameters used in the ICP-MS equipment were air flow $13.50 \mathrm{~L} / \mathrm{min}$, acetylene flow $2.00 \mathrm{~L} / \mathrm{min}$, burner height $13.50 \mathrm{~mm}$, slit width $0.2-1.0 \mathrm{~nm}$, and lamp current $4-10 \mathrm{~mA}$.

\section{Results and Discussion}

\section{1. ${ }^{13} \mathrm{C}$ and ${ }^{29} \mathrm{Si}$ NMR Analysis}

Radical grafting from polymerization of $\mathrm{Q}$ on $\mathrm{VTMSO}-\mathrm{SiO}_{2}$ particles requires three working steps: (a) silica activation; (b) functionalization of silica with vinyltrimethoxysilane to form silica-C $=\mathrm{C}\left(\mathrm{VTMSO}-\mathrm{SiO}_{2}\right)$; and (c) functionalization of $\mathrm{VTMSO}-\mathrm{SiO}_{2}$ with $\mathrm{Q}$ to form silica- $\mathrm{N}^{+}\left(\mathrm{CH}_{3}\right)_{3}$ $\left(\mathrm{Q} / \mathrm{VTMSO}-\mathrm{SiO}_{2}\right)$. Figure 1 shows the ${ }^{29} \mathrm{Si} \mathrm{NMR}$ spectra of a typical Q/VTMSO-SiO ${ }_{2}$ sample and the VTMSO-SiO ${ }_{2}$ and silica precursors.

The ${ }^{29} \mathrm{SiNMR}$ spectrum of silica gel for chromatography is shown in Figure 1a and shows typical peaks at $-11.88,-101.61$, and $-91.48 \mathrm{ppm}$, which can be identified with silicon sites in a reasonable surface model. These signals are assigned to the silicon atoms bound to four other oxygens called $Q^{4}$ moieties at the silica gel surface, to the surface silicon atoms attached to three oxygens $\left(Q^{3}\right)$ moieties and one $\mathrm{OH}$ group, and finally the $-91.48 \mathrm{ppm}$ resonance is assigned to surface silicon atoms bonded to two oxygen and two hydroxyl groups, respectively. It is important to note that these values are in reasonable qualitative agreement with the values found by ${ }^{29} \mathrm{Si} \mathrm{CP} / \mathrm{MAS}$ for silica reported by Kedong et al. [36]. Figure $1 \mathrm{~b}$ shows the $\mathrm{VTMSO}-\mathrm{SiO}_{2}$ spectra; the signals corresponding to $\mathrm{Q}^{3}$ and $\mathrm{Q}^{4}$ decrease in contrast to the $\mathrm{Q}^{2}$ shift, which virtually disappears, thus verifying the silylation of silica gel. Meanwhile, three new peaks, $\mathrm{T}^{3}, \mathrm{~T}^{2}$, and $\mathrm{T}^{1}$, are generated, indicating that the VTMSO was triply, doubly, and singly bonded to silica particles. Finally, we obtained the spectra of Q/VTMSO-SiO (Figure 1c). The remarkable feature in this spectrum is the decrease in intensity of the region where the $\mathrm{T}$ sites appear, thus corroborating the successful radical grafting from polymerization of $\mathrm{Q}$ on silica.
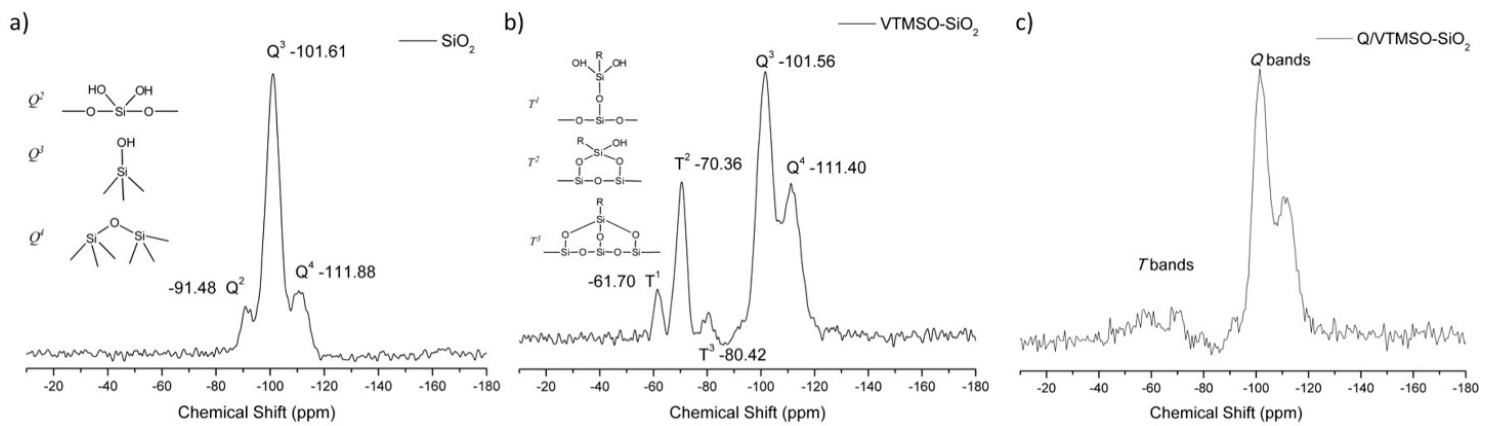

Figure 1. Solid-state ${ }^{29} \mathrm{Si} \mathrm{NMR}$ spectra of $\mathrm{SiO}_{2}(\mathbf{a}), \mathrm{VTMSO}-\mathrm{SiO}_{2}(\mathbf{b})$, and Q/VTMSO-SiO 2 (c). Inset: possible structure details with signal assignment.

Figure 2 shows the solid state ${ }^{13} \mathrm{C}$ NMR spectra of $\mathrm{VTMSO}-\mathrm{SiO}_{2}$ and Q/VTMSO-SiO 2 . The VTMSO-SiO ${ }_{2}$ spectra is characterized by three signals corresponding to the carbons that form double bonds and a methyl group founded in 134.16, 128.83, and $48.59 \mathrm{ppm}$, respectively. The $\mathrm{Q}$ molecule has one carbonyl, two methylene bridges, three methyl groups, and one double bond, and its molecular structure attached to the functionalized silica gel has been verified based on a comparison of the solid state ${ }^{13} \mathrm{C}$ NMR spectra of $\mathrm{Q} / \mathrm{VTMSO}-\mathrm{SiO}_{2}$ and $\mathrm{VTMSO}-\mathrm{SiO}_{2}$. The Q/VTMSO-SiO 2 spectra is characterized by the almost disappearance of the ethenic double bond signs as a result of the radical grafting from polymerization of $Q$ on silica. The presence of vinylics signs is probably a consequence of double bonds belonging to a VTMSO-SiO 2 that is not spatially available for polymerization. Furthermore, the generation of a new sign centered in approximately $40 \mathrm{ppm}$ corresponds to the $\mathrm{CH}_{2}$ 
groups of the skeleton of the polymeric chain and the other signals corresponding to the molecular structure of $\mathrm{Q}$, corroborating the presence of $\mathrm{Q}$ on $\mathrm{VTMSO}-\mathrm{SiO}_{2}$. The $\mathrm{Q} / \mathrm{VTMSO}-\mathrm{SiO}_{2}$ spectra data agree with the results reported by Oscar et al. [37]. However, it was difficult to be certain from these spectra how many $Q$ and VTMS molecules reacted with silica gel. We solved this problem using the thermogravimetry technique and the results will be discussed later.

a)

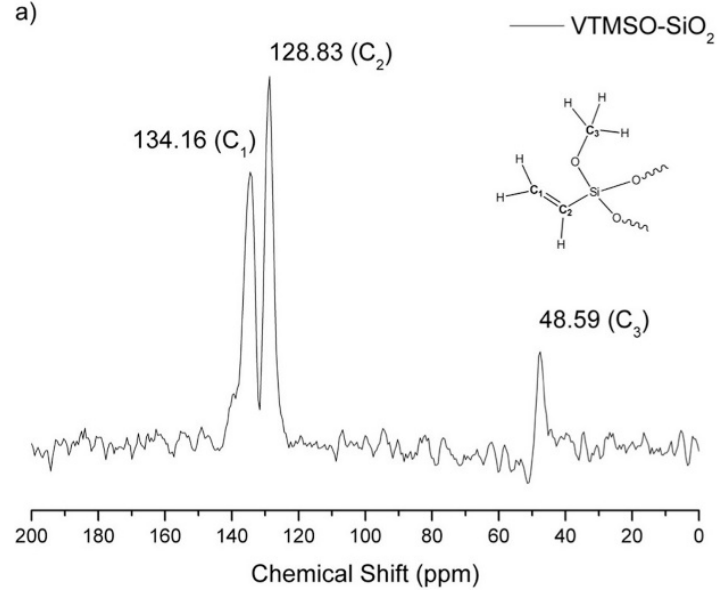

b)

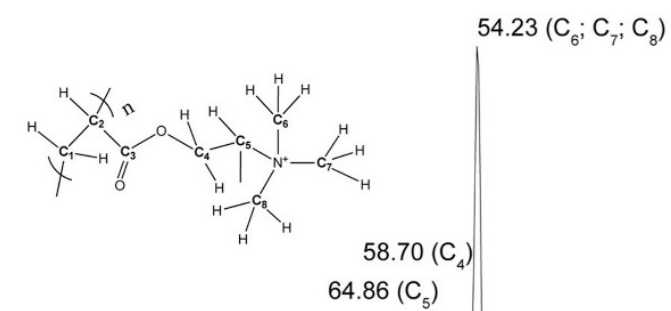

$\left(C_{p}\right)$

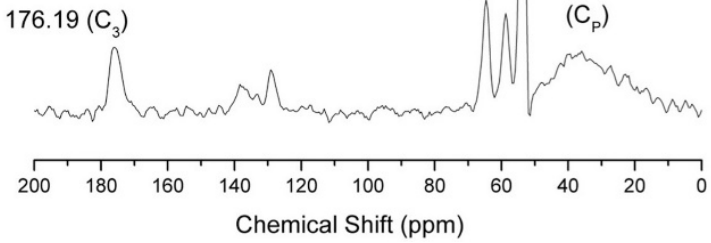

Figure 2. Solid-state ${ }^{13} \mathrm{C}$ NMR spectrum of $\mathrm{VTMSO}-\mathrm{SiO}_{2}(\mathbf{a})$ and $\mathrm{Q} / \mathrm{VTMSO}-\mathrm{SiO}_{2}(\mathbf{b})$. Inset: structure details with signal assignment.

\subsection{FT-IR Analysis}

Therefore, the processing FT-IR spectroscopy was performed for $\mathrm{SiO}_{2}, \mathrm{VTMSO}-\mathrm{SiO}_{2}$ and $\mathrm{Q} / \mathrm{VTMSO}-\mathrm{SiO}_{2}$ to examine their chemical structures. These spectra are compared in Figure $3 \mathrm{a}-\mathrm{c}$, respectively. In all samples there were strong characteristic absorption peaks that were assigned to the silane carbon bonds, $\mathrm{Si}-\mathrm{CH}$ at $800 \mathrm{~cm}^{-1}$ and absorption peaks at around the $1100 \mathrm{~cm}^{-1}$ region characteristic of the methoxy groups $\mathrm{Si}-\mathrm{OCH}_{3}$ and any siloxane cross-links ( $\mathrm{Si}-\mathrm{O}-\mathrm{Si}$ ) that were formed during the silylation of silica by VTMSO. Also, we observed the absorption bands of $\mathrm{OH}$ stretching at $3432 \mathrm{~cm}^{-1}$ and $\mathrm{H}-\mathrm{O}-\mathrm{H}$ bending at $1634 \mathrm{~cm}^{-1}$ characteristic of silica. It is important to note that in the FT-IR spectra of VTMSO-SiO 2 the signal corresponding to the vinyl group overlapped due to the intensity of the other silica signals.

However, comparing the $\mathrm{SiO}_{2}$ and $\mathrm{VTMSO}-\mathrm{SiO}_{2}$ spectra, the changes of intensities, shape, and position of the silica signals in the $1100-800 \mathrm{~cm}^{-1}$ region indicated that silane grafting reactions had occurred. Finally, the Q/VTMSO-SiO 2 spectra show characteristic absorption bands corresponding to the principal functional groups present in the $\mathrm{Q}$ molecule and $\mathrm{VTMSO}-\mathrm{SiO}_{2}$. Thus, the spectrum showed a broad structureless band at $3493 \mathrm{~cm}^{-1}$ because of the $\mathrm{OH}$ groups, two peaks at 1734 and $1481 \mathrm{~cm}^{-1}$, which were assigned to a $\mathrm{C}=\mathrm{O}$ and $\mathrm{N}^{+}\left(\mathrm{CH}_{3}\right)_{3}$ groups, respectively, and one sharp peak at $1198 \mathrm{~cm}^{-1}$, which is for the $\mathrm{C}-\mathrm{O}$ group. At $956 \mathrm{~cm}^{-1}$ there appears as a singular band presented in the $\mathrm{Q}$ monomer spectrum, which may be related to the $\mathrm{C}-\mathrm{O}$ stretching vibration in a $-\mathrm{O}-$ fragment [38]. Bands at $2965 \mathrm{~cm}^{-1}$ (CH stretching) and $1500-1300 \mathrm{~cm}^{-1}$ (various $\mathrm{C}-\mathrm{H}$ bending) were also detected. All these indicate that the synthesized particles have combined chemical structures of silica, VTMSO, and $\mathrm{Q}$, corroborating the results obtained by ${ }^{29} \mathrm{Si}$ and ${ }^{13} \mathrm{C}$ NMR. 

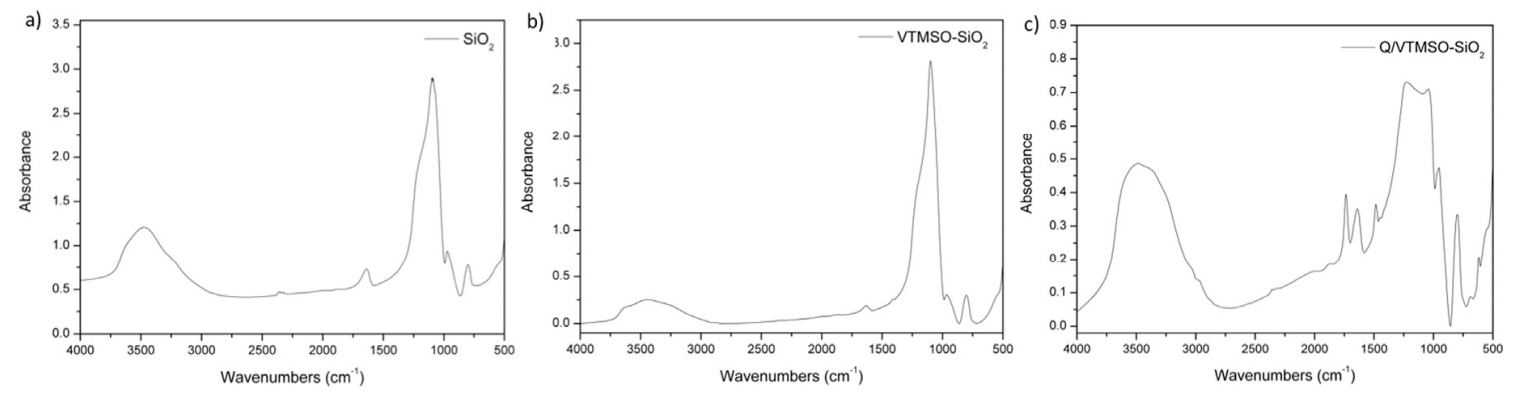

Figure 3. FT-IR spectrum of $\mathrm{SiO}_{2}(\mathbf{a}), \mathrm{VTMSO}-\mathrm{SiO}_{2}(\mathbf{b})$, and $\mathrm{Q} / \mathrm{VTMSO}-\mathrm{SiO}_{2}$ (c).

\subsection{TGA Analysis}

The thermogravimetric analysis (TGA and derivate) of $\mathrm{SiO}_{2}, \mathrm{VTMSO}_{-} \mathrm{SiO}_{2}$, and Q/VTMSO-SiO are shown in Figure $4 \mathrm{a}-\mathrm{c}$, respectively. These studies resulted in some interesting information about the thermal stability and fraction weight loss of prepared compounds. Figure $4 \mathrm{a}$ shows that the thermogram obtained for $\mathrm{SiO}_{2}$ had a first loss of $14.90 \%$ until $62{ }^{\circ} \mathrm{C}$ due to physically adsorbed methanol, and a second loss in the range of $110-800{ }^{\circ} \mathrm{C}$ corresponding to the condensation of surface silanol groups. As for $\mathrm{VTMSO}-\mathrm{SiO}_{2}$, the high temperature required to decompose and evaporate the organic content of the silanized silica demonstrated that the silane coupling agent (VTMSO) was strongly bound to the particle surface and suggested a covalent bond (see Figure $4 \mathrm{~b}$ ). This decomposition event starting at $500^{\circ} \mathrm{C}$ corresponded to the decomposition temperature of VTSMO covalently attached to silica particles, and the weight loss was $6.59 \%$. Calculations based on TGA showed that the grafting density of grafted vinyl group is $0.235 \mathrm{mmol} / \mathrm{m}^{2}$ according to Equation (1).
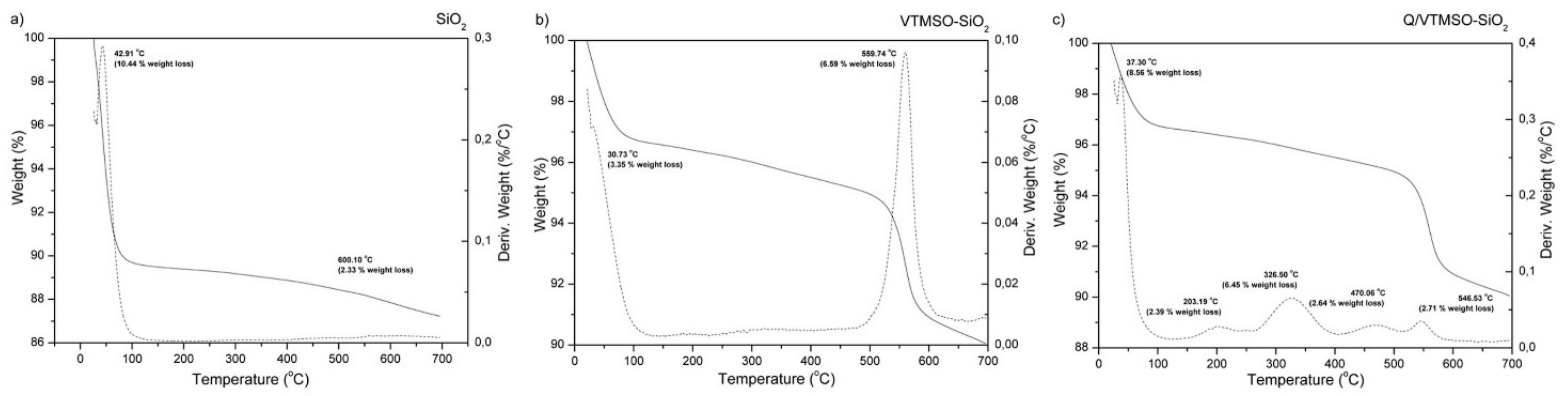

Figure 4. TG-DTG thermograms of $\mathrm{SiO}_{2}(\mathbf{a}), \mathrm{VTMSO}^{-\mathrm{SiO}_{2}}$ (b), and Q/VTMSO-SiO 2 (c).

The thermogram corresponding to the decomposition of $\mathrm{Q} / \mathrm{VTMSO}-\mathrm{SiO}_{2}$ showed quite a different mechanism (see Figure $4 \mathrm{c}$ ) due to the $\operatorname{poly}(\mathrm{Q})$ presence in the silanized silica. Its decomposition occurred in five steps starting at $120,256,408$, and $516^{\circ} \mathrm{C}$, respectively. The total weight loss was about $23 \%$ of the $\mathrm{Q} / \mathrm{VTMSO}-\mathrm{SiO}_{2}$ degradable part. The degradation mechanism consisted in random chain scissions and the ammonium salt decomposition in the case of poly $(\mathrm{Q})$, the polymer grafting was $14.36 \%$. On the other hand, it could be that the presence of a VTMSO degradation signal at high temperature was due to the vinyl group that is not available spatially for polymerization. The obtained poly $(\mathrm{Q})$ degradation data agreed with the results reported by Oscar et al. [38]. Finally, it is important to note that the slight weight loss, about $6 \%$, of three thermograms observed at around $40{ }^{\circ} \mathrm{C}$ was likely caused by the methanol used in washing. These results reinforced the data obtained by FT-IR, ${ }^{13} \mathrm{C}$, and ${ }^{29} \mathrm{Si} \mathrm{NMR}$.

\subsection{XRD Analysis}

The XRD analysis of $\mathrm{SiO}_{2}$, VTMSO-SiO 2 , and Q/VTMSO-SiO ${ }_{2}$ showed that the amorphous condition of the silica was unaffected by the silylation and grafting processes (See Figure 5). Thus, 
we observe no apparent change in XRD patterns. The XRD pattern of three materials displayed two intense peaks in the $2 \theta$ range of $0.9-2.5$, which is associated to the thin monolayer of trimethylsilyl moiety and the amorphous diffraction peak of silica-gel. In general, after silylation and grafting processes, the first peak increased the intensity due to the VTMSO presence. In conclusion, the XRD patterns suggested that surface treatment of silica had no evident effect on its crystal structure.
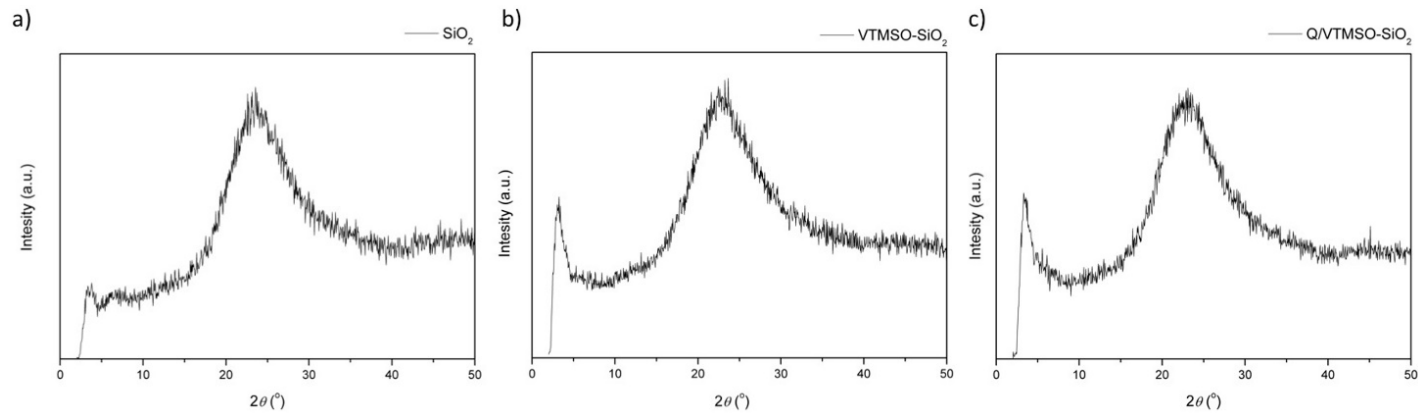

Figure 5. XRD patterns of $\mathrm{SiO}_{2}(\mathbf{a}), \mathrm{VTMSO}-\mathrm{SiO}_{2}(\mathbf{b})$, and $\mathrm{Q} / \mathrm{VTMSO}-\mathrm{SiO}_{2}$ (c).

\subsection{SEM Analysis}

Morphologies of the silica particles before/after were observed to examine the difference in morphologies aroused by the VTMSO coating and Q grafting, respectively. Figure 6 shows the SEM images of $\mathrm{SiO}_{2}, \mathrm{VTMSO}-\mathrm{SiO}_{2}$, and Q/VTMSO-SiO 2 with different magnifications. The silica particles looked like a crystal had an irregular cubic shape and a polydispersed size. In addition, the silica particles had a smooth and clean surface. After modification by VTMSO and Q, the particle surface became rougher and decreased in size, but they maintained their irregular shape (see Figure 6b). It is important to note that the addition of $Q$ over silanized silica particles decreased in size even more. This is because the surface of Q/VTMSO-SiO 2 contained a large number of quaternary ammonium groups that did not interact and the $\mathrm{OH}$ groups of silica decreased dramatically. Finally, the particle surface was covered with nanoscale lumps, which were believed to be the VTMSO and poly(Q) coating in the case of VTMSO-SiO 2 and Q/VTMSO-SiO 2 , respectively.
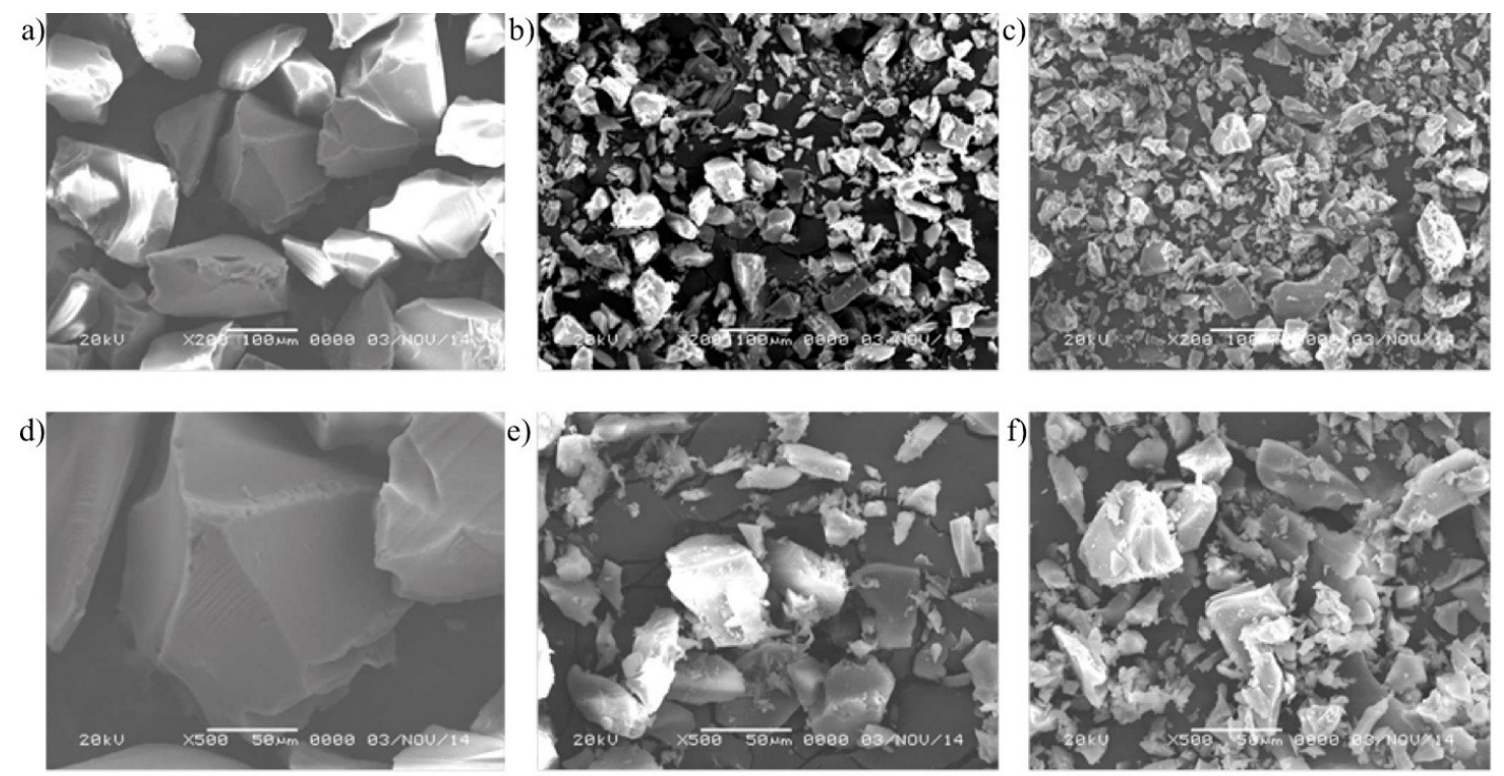

Figure 6. Cont. 

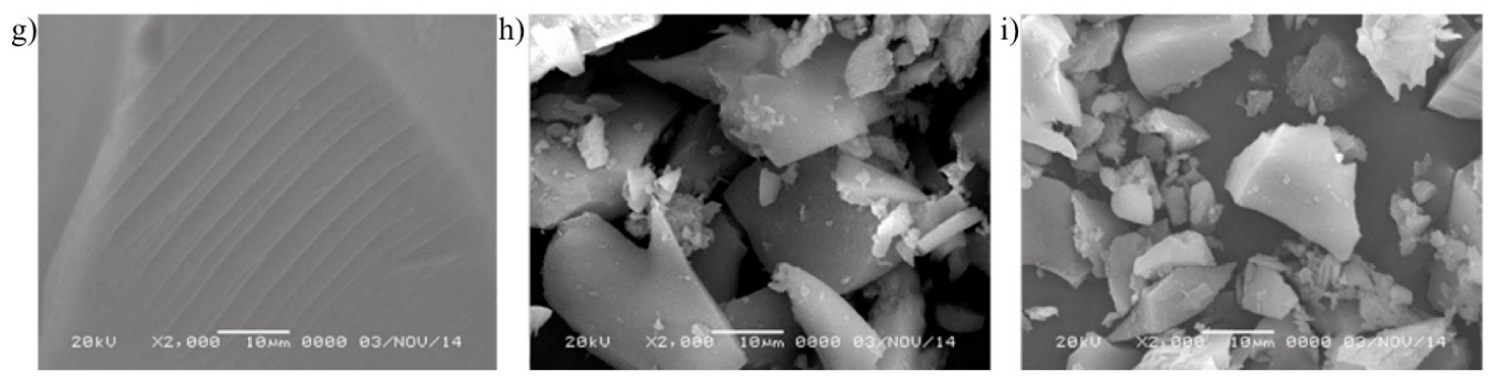

Figure 6. SEM images of $\mathrm{SiO}_{2}(\mathbf{a}, \mathbf{d}, \mathbf{g}), \mathrm{VTMSO}-\mathrm{SiO}_{2}(\mathbf{b}, \mathbf{e}, \mathbf{h})$, and $\mathrm{Q} / \mathrm{VTMSO}-\mathrm{SiO}_{2}(\mathbf{c}, \mathbf{f}, \mathbf{i})$ with different magnifications.

\subsection{Arsenic Retention Properties of Q/VTMSO-SiO 2}

In Figure 7, the results of affinity assays between Q/VTMSO-SiO $\mathrm{S}_{2}$ and model arsenic solution are shown. In elutions 1 and 2, the cartridge was able to capture all the arsenic present in the model solution. In the third elution, the capture capacity of the cartridge decreased to $97.7 \%$. The fourth elution showed a capture capacity of $74.9 \%$. In the fifth elution, the cartridge capture capacities fell to $48.2 \%$. Finally, in the sixth elution, the cartridge capture capacities were only $19 \%$.

Considering these results, $1 \mathrm{~g}$ of Q/VTMSO-SiO 2 could treat up to $320 \mathrm{~mL}$ of $0.1 \mathrm{mg} \cdot \mathrm{mL}^{-1}$ arsenic solution, capturing the total amount of arsenic. If we want to decrease the concentration of arsenic to a half value, we can treat up to $800 \mathrm{~mL}$ of $0.1 \mathrm{mg} \cdot \mathrm{mL}^{-1}$ arsenic solution. Scaling these results, if we use a filter filled with $1 \mathrm{~kg}$ of $\mathrm{Q} / \mathrm{VTMSO}-\mathrm{SiO}_{2}$, we can treat $320 \mathrm{~L}$ of water with arsenic concentration of $0.1 \mathrm{mg} \cdot \mathrm{mL}^{-1}$, capturing $100 \%$ of the present arsenic. If we want to get to the international limits of arsenic in drinkable water $\left(0.05 \mathrm{mg} \cdot \mathrm{mL}^{-1}\right)$, we can treat up to $800 \mathrm{~L}$.

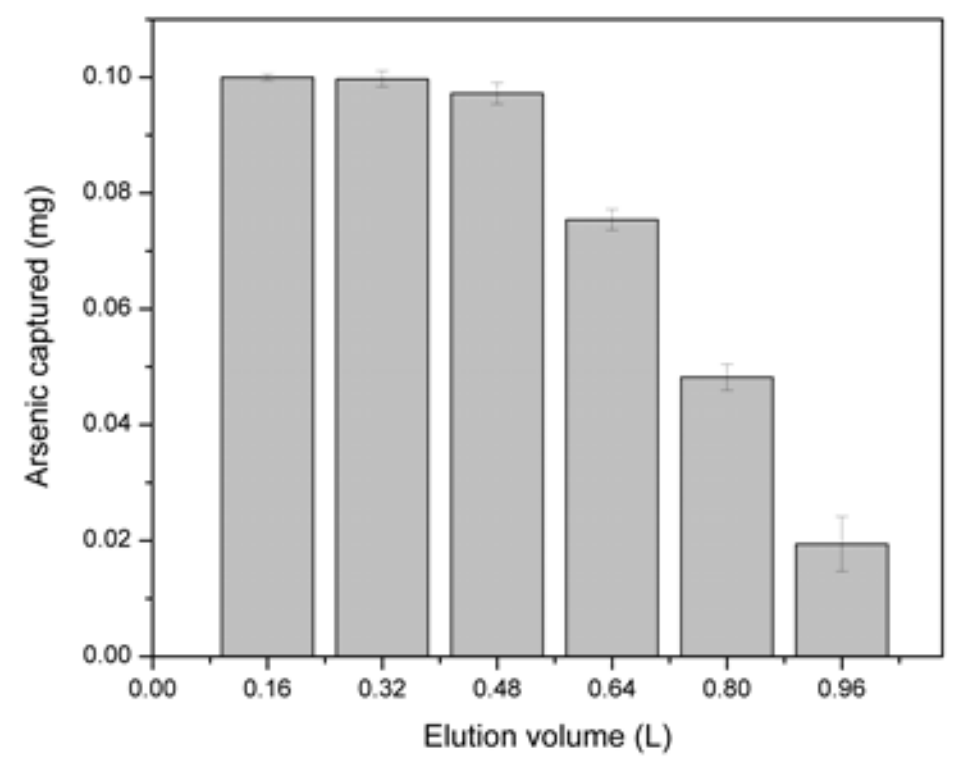

Figure 7. Affinity assays between Q/VTMSO-SiO 2 and arsenic solution $\left(0.1 \mathrm{mg} \cdot \mathrm{L}^{-1}\right)$.

\subsection{Metal Affinities of Q/VTMSO-SiO ${ }_{2}$ Fill and Commercial Water Filter Fill}

We compared the capacity of removing metal contaminants in drinking water using $\mathrm{Q} / \mathrm{VTMSO}-\mathrm{SiO}_{2}$ fill and a fill obtained from commercial water filters acquired from a commercial store. Table 1 present the results of the experimental design used to evaluate the affinity of fill from commercial water filters. 
Table 1. Experiments for affinity by As performed using fill from commercial water filters.

\begin{tabular}{ccccc}
\hline Experiment & As concentration $\left[\boldsymbol{\mu} \mathbf{g} \cdot \mathbf{L}^{-\mathbf{1}}\right]$ & Volume $[\mathbf{m L}]$ & As captured $\left[\boldsymbol{\mu} \mathbf{g} \cdot \mathbf{L}^{-\mathbf{1}}\right.$ ] & As capture rate $[\%]$ \\
\hline 1 & $16.38(-)$ & $100(-1)$ & 0.130 & 0.790 \\
2 & $16.38(-1)$ & $500(1)$ & 4.52 & 27.6 \\
3 & $87.42(-0.64)$ & $100(-1)$ & 3.24 & 3.71 \\
4 & $87.42(-0.64)$ & $500(1)$ & 5.27 & 6.03 \\
5 & $409.2(1)$ & $100(-1)$ & 26.7 & 6.52 \\
6 & $409.2(1)$ & $500(1)$ & 9.20 & 2.25 \\
7 & $87.42(-0.64)$ & $300(0)$ & 8.80 & 10.1 \\
8 & $87.42(-0.64)$ & $300(0)$ & 10.9 & 12.5 \\
9 & $87.42(-0.64)$ & $300(0)$ & 11.2 & 12.8 \\
\hline
\end{tabular}

Numbers between parentheses indicate the entry sequenced dataset for statistical analysis.

The results obtained using the experimental design are shown through a Pareto chart. In Figure 8, the Pareto chart and estimated response surface for the As capture experiments are presented using the fill from commercial water filters.

Considering the statistical significance of the variables, the equation of the model is:

$$
\text { As Capture Rate }=3.55-4.90 \times A+2.87 \times B-6.00 \times A \times B\left(R^{2}=37.28\right) .
$$

According to the model, the optimum As capture predicted by this filter fill was $23.06 \%$. The optimum experimental conditions were a volume of $500 \mathrm{~mL}$ and a concentration of $16.38 \mathrm{ppb}$. In this way, this filter fill would allow the treatment of $500 \mathrm{~mL}$ of drinking water contaminated with As, reducing its concentration from 16.38 to $12.6 \mathrm{ppb}$ of As.

Following the same procedure, we tested $\mathrm{Q} / \mathrm{VTMSO}-\mathrm{SiO}_{2}$ under the optimum experimental conditions, measuring the affinity for metals naturally present in drinking water. Table 2 presents the results of the experimental design used to evaluate the affinity of Q/VTMSO-SiO${ }_{2}$.

a)

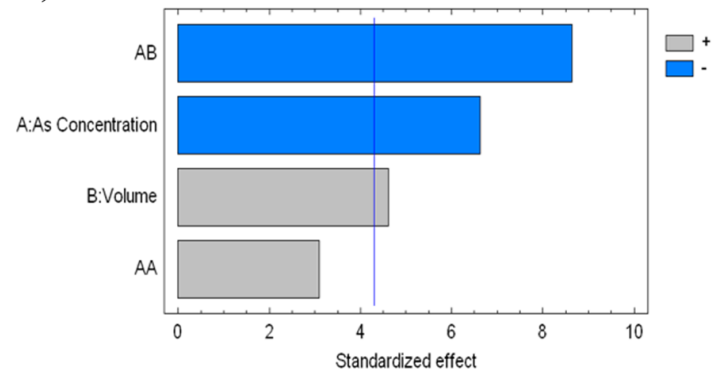

b)

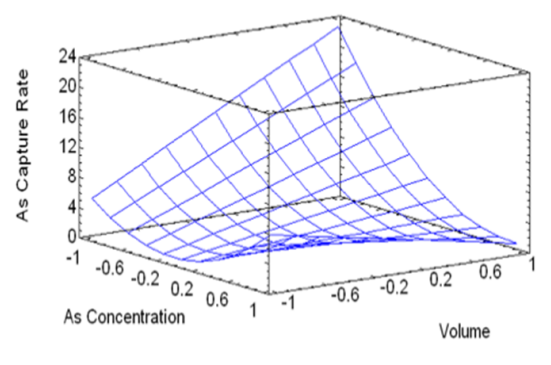

Figure 8. (a) Standardized Pareto chart for As capture rate, due to commercial polymer treatment (where: A, As concentration; B, Eluted volume; and AB, AA and BB interactions. Blue line represents critical $t$-value, $95 \%$ confidence); and (b) estimated response surface.

Table 2. Experiments for affinity by As, performed using Q/VTMSO-SiO 2 .

\begin{tabular}{ccccc}
\hline Experiment & As concentration $\left[\boldsymbol{\mu g} \cdot \mathbf{L}^{-\mathbf{1}}\right]$ & Volume $[\mathbf{m L}]$ & As captured $\left[\boldsymbol{\mu g} \cdot \mathbf{L}^{-\mathbf{1}}\right]$ & As capture rate $[\%]$ \\
\hline 1 & $16.38(-1.00)$ & $100(-1)$ & 4.31 & 26.30 \\
2 & $16.38(-1.00)$ & $500(1)$ & 5.05 & 30.80 \\
3 & $87.42(-0.64)$ & $100(-1)$ & 25.20 & 28.80 \\
4 & $87.42(-0.64)$ & $500(1)$ & 8.33 & 9.530 \\
5 & $409.2(1.00)$ & $100(-1)$ & 156.00 & 38.20 \\
6 & $409.2(1.00)$ & $500(1)$ & 80.90 & 19.80 \\
7 & $87.42(-0.64)$ & $300(0)$ & 14.90 & 17.00 \\
8 & $87.42(-0.64)$ & $300(0)$ & 14.20 & 16.50 \\
9 & $87.42(-0.64)$ & $300(0)$ & 14.50 & \\
\hline
\end{tabular}

Numbers between parentheses indicate entry sequenced data set for statistical analysis. 
Based on the results obtained, Figure 9 shows the Pareto chart and the estimated response surface for the As capture experiments using $\mathrm{Q} / \mathrm{VTMSO}-\mathrm{SiO}_{2}$ in drinking water.

a)

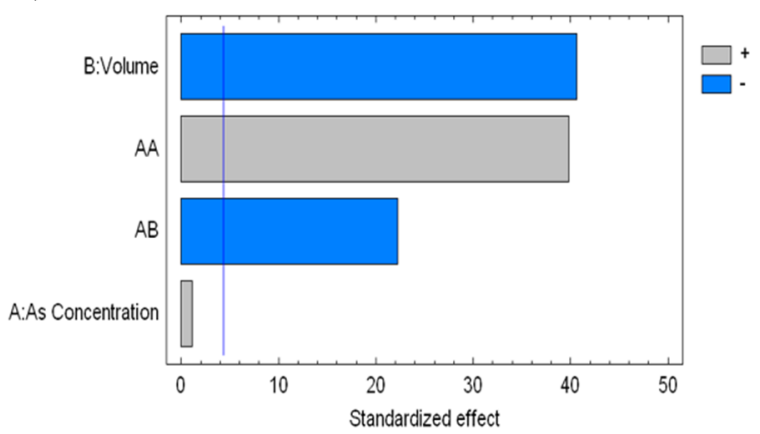

b)

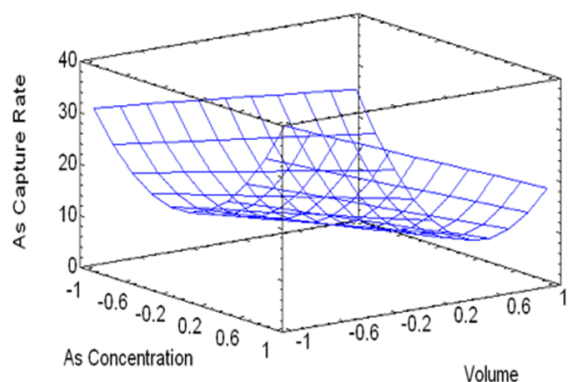

Figure 9. (a) Standardized Pareto chart for As capture rate, due to $\mathrm{Q} / \mathrm{VTMSO}-\mathrm{SiO}_{2}$ filler treatment (where: A, As concentration; B, Eluted volume; and $\mathrm{AB}, \mathrm{AA}$ and $\mathrm{BB}$ interactions. Blue line represents critical $t$-value, 95\% confidence); and (b) estimated response surface.

According to the statistical significance of the variables, the equation of the model is:

$$
\text { As Capture Rate }=10.2-6.36 \times B+18.6 \times A^{2}-3.90 \times A \times B\left(R^{2}=65.57\right) .
$$

The optimum As capture predicted for Q/VTMSO-SiO ${ }_{2}$ fill was $39.24 \%$. The optimum experimental conditions were a volume of $100 \mathrm{~mL}$ and a concentration of $409.2 \mathrm{ppb}$. In this way, the use of this filter fill would allow the treatment of $100 \mathrm{~mL}$ of drinking water contaminated with As, reducing its concentration from 409.2 to $248.6 \mathrm{ppb}$ of As. In addition, $500 \mathrm{~mL}$ of As-contaminated water can be treated at $16.38 \mathrm{ppb}$, decreasing its concentration to $11.33 \mathrm{ppb}$. The differences observed between the model solution using MilliQ water and drinking water enriched with As are due to the presence of other metals in solution, generating competition for the retention of other metals present.

Finally, considering the experimental conditions in which the commercial polymer presented a better performance, the experimental conditions of the second experiment (Tables 1 and 2) were selected and the affinity of both polymers to other metals present in the drinking water was determined. The results are shown in Figure 10. It is observed that the commercial polymer has a lower affinity than $\mathrm{Q} / \mathrm{VTMSO}-\mathrm{SiO}_{2}$ for all the metals present in the drinking water used.

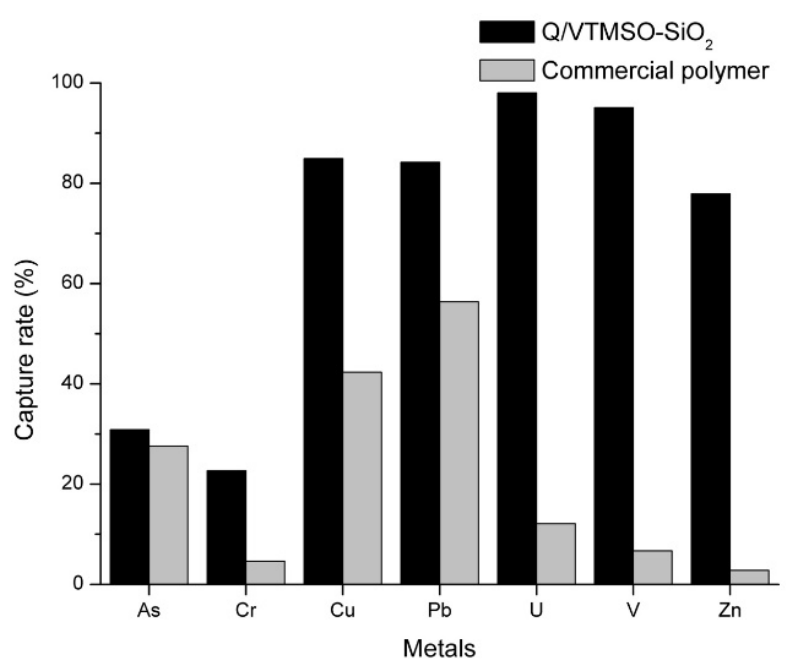

Figure 10. Capture rate of some heavy metals present in drinking water by the commercial polymer and Q/VTMSO-SiO 2 . 


\section{Conclusions}

In summary, new silica hybrid particles were made available by a two-step synthesis. In the first step, silica particles are functionalized with vinyltrimethoxysilane; secondly, they are radically copolymerized with $\mathrm{Q}$. The product was fully characterized and tested for its ability to remove arsenic and other metals present. Remediation of arsenate anions was successfully achieved using $\mathrm{Q} / \mathrm{VTMSO}-\mathrm{SiO}_{2}$. The results showed that $1 \mathrm{~g}$ of $\mathrm{Q} / \mathrm{VTMSO}-\mathrm{SiO}_{2}$ could treat up to $320 \mathrm{~mL}$ of $0.1 \mathrm{mg} \cdot \mathrm{mL}^{-1}$ arsenic solution, capturing the total amount of arsenic from drinking water. In addition, $\mathrm{Q} /$ VTMSO-SiO ${ }_{2}$ showed better sorption capacities for other metal ions such as copper, zinc, chromium, uranium, vanadium, and lead than the fill from a commercial water filter. These results suggest that the strategy of using modified silica with quaternary ammonium groups onto surfaces could lead to new devices for drinking water purification.

Author Contributions: Conceptualization, O.V. and L.S.S.; Methodology, O.V.; Validation, O.V., A.M. and Y.M.-G.; Resources, L.S.S.; Data Curation, O.V., A.M. and Y.M.-G.; Writing-Original Draft Preparation, O.V., A.M. and Y.M.-G.; Writing-Review \& Editing L.S.S.; Project Administration, O.V.

Acknowledgments: The project was supported by PIEI-QuiBio (UTALCA), Fondecyt (No. 11170008, 3140293 and 1180084), and The Academic Writing Center at the Programa de Idiomas of the Universidad de Talca.

Conflicts of Interest: The authors declare no conflicts of interest.

\section{References}

1. Mohan, D.; Pittman, C.U., Jr. Arsenic removal from water/wastewater using adsorbents-A critical review. J. Hazard. Mater. 2007, 142, 1-53. [CrossRef] [PubMed]

2. Saha, J.C.; Dikshit, A.K.; Bandyopadhyay, M.; Saha, K.C. A Review of Arsenic Poisoning and its Effects on Human Health. Environ. Sci. Technol. 1999, 29, 281-313. [CrossRef]

3. Kapaj, S.; Peterson, H.; Liber, K.; Bhattacharya, P. Human Health Effects from Chronic Arsenic Poisoning-A Review. J. Environ. Sci. Health A 2006, 41, 2399-2428. [CrossRef] [PubMed]

4. World Health Organization. Guidelines for Drinking-Water Quality, 3rd ed.; WHO: Geneva, Switzerland, 2008; Volume 1.

5. Melamed, D. Monitoring Arsenic in the Environment: A Review of Science and Technologies for Field Measurements and Sensors; EPA Report 542/R-04/002; U.S. Environmental Protection Agency: Washington, DC, USA, 2004; pp. $1-23$.

6. Malik, A.H.; Khan, Z.M.; Mahmood, Q.; Nasreen, S.; Bhatti, Z.A. Perspectives of low cost arsenic remediation of drinking water in Pakistan and other countries. J. Hazard. Mater. 2009, 168, 1-12. [CrossRef] [PubMed]

7. Moreno-Villoslada, I.; Rivas, B.L. Competition of Divalent Metal Ions with Monovalent Metal Ions on the Adsorption on Water-Soluble Polymers. J. Phys. Chem. B 2002, 106, 9708-9711. [CrossRef]

8. Rivas, B.L.; Aguirre, M.D.C.; Pereira, E. Retention Properties of Arsenate Anions of Water-Soluble Polymers by a Liquid-Phase Polymer-Based Retention Technique. J. Appl. Polym. Sci. 2006, 102, 2677-2684. [CrossRef]

9. Rivas, B.L.; Aguirre, M.D.C.; Pereira, E.; Moutet, J.-C.; Aman, E.S. Capability of Cationic Water-Soluble Polymers in Conjunction With Ultrafiltration Membranes to Remove Arsenate Ions. Polym. Eng. Sci. 2007, 47, 1256-1261. [CrossRef]

10. Sánchez, J.; Rivas, B.L. Arsenic extraction from aqueous solution: Electrochemical oxidation combined with ultrafiltration membranes and water-soluble polymers. Chem. Eng. J. 2010, 165, 625-632. [CrossRef]

11. Milner, S.T. Polymer brushes. Science 1991, 251, 905-914. [CrossRef] [PubMed]

12. Wang, L.P.; Wang, Y.P.; Wang, R.M.; Zhang, S.C. Preparation of polymer brushes on palygorskite surfaces via RAFT polymerization. React. Funct. Polym. 2008, 68, 643-648. [CrossRef]

13. Granville, A.M.; Boyes, S.G.; Akgun, B.; Foster, M.D.; Brittain, W.J. Thermo-responsive behavior of semi-fluorinated polymer brushes. Macromolecules 2005, 38, 3263-3270. [CrossRef]

14. Zhou, Q.; Fan, X.; Xia, C.; Mays, J.; Advincula, R. Living anionic surface initiated polymerization (SIP) of styrene clay surfaces. Chem. Mater. 2001, 13, 2465-2467. [CrossRef]

15. Fan, X.; Xia, C.; Fulghum, T.; Park, M.K.; Locklin, J.; Advincula, R. Polymer brushes grafted from clay nanoparticles adsorbed on a planar substrate by free radical surface-initiated polymerization. Langmuir 2003, 19, 916-923. [CrossRef] 
16. Rider, D.A.; Chen, J.I.L.; Eloi, J.C. Controlling the morphologies of organometallic block copolymers in the 3-dimensional spatial confinement of colloidal and inverse colloidal crystals. Macromolecules 2008, 41, 2250-2259. [CrossRef]

17. Norde, W.; Gags, D. Interaction of bovine serum albumin and human blood plasma with PEO-tethered surfaces: Influence of PEO chain length, grafting density, and temperature. Langmuir 2004, 20, 4162-4167. [CrossRef] [PubMed]

18. Lahiri, J.; Isaacs, L.; Grzybowski, B.; Carbeck, J.D.; Whitesides, G.M. Biospecifîc binding of carbonic anhydrase to mixed SAMs presenting benzenesulfonamide ligands: A model system for studying lateral steric effects. Langmuir 1999, 15, 7186-7198. [CrossRef]

19. Hucknall, A.; Rangarajan, S.; Chilkoti, A. In pursuit of zero: Polymer brushes that resist the adsorption of proteins. Adv. Mater. 2009, 21, 2441-2446. [CrossRef]

20. Kataoka, D.E.; Troian, S.M. Patterning liquid flow on the microscopic scale. Nature 1999, 402, $794-797$. [CrossRef]

21. Zhao, B.; Brittain, W.J. Polymer brushes: Surface-immobilized macromolecules. Prog. Polym. Sci. 2000, 25, 677-710. [CrossRef]

22. Park, J.W.; Thomas, E.L. A surface-reactive rod-coil diblock copolymer: Nano- and micropatterned polymer brushes. J. Am. Chem. Soc. 2002, 124, 514-515. [CrossRef] [PubMed]

23. Gong, F.; Feng, M.; Zhao, C.; Zhang, S.; Yang, M. Thermal properties of poly(vinyl chloride)/montmorillonite nanocomposites. Polym. Degrad. Stab. 2004, 84, 289-294. [CrossRef]

24. Zheng, H.; Zhang, Y.; Peng, Z.; Zhang, Y. Influence of clay modification on the structure and mechanical properties of EPDM/montmorillonite nanocomposites. Polym. Test. 2004, 23, 217-223. [CrossRef]

25. Lee, J.Y.; Lee, H.K. Characterization of organobentonite used for polymer nanocomposites. Mater. Chem. Phys. 2004, 85, 410-415. [CrossRef]

26. Gong, F.; Feng, M.; Zhao, C.; Zhang, S.; Yang, M. Particle configuration and mechanical properties of poly(vinyl chloride)/montmorillonite nanocomposites via in situ suspension polymerization. Polym. Test. 2004, 23, 847-853. [CrossRef]

27. Tully, D.C.; Trimble, A.R.; Fréchet, J.M.J.; Wilder, K.; Quate, C.F. Synthesis and preparation of ionically bound dendrimer monolayers and application toward scanning probe lithography. Chem. Mater. 1999, 11, 2892-2898. [CrossRef]

28. Zhao, B.; Brittain, W.J. Synthesis of polystyrene brushes on silicate substrates via carbocationic polymerization from self-assembled monolayers. Macromolecules 2000, 33, 342-348. [CrossRef]

29. Tran, Y.; Auroy, P. Synthesis of poly(styrene sulfonate) brushes. J. Am. Chem. Soc. 2001, 123, 3644-3654. [CrossRef] [PubMed]

30. Mansky, P.; Liu, Y.; Huang, E.; Russell, T.P.; Hawker, C. Controlling polymer-surface interactions with random copolymer brushes. Science 1997, 275, 1458-1460. [CrossRef]

31. Prucker, O.; Rühe, J. Synthesis of poly(styrene) monolayers attached to high surface area silica gels through self-assembled monolayers of azo initiators. Macromolecules 1998, 31, 592-601. [CrossRef]

32. Prucker, O.; Rühe, J. Mechanism of radical chain polymerizations initiated by azo compounds covalently bound to the surface of spherical particles. Macromolecules 1998, 3, 602-613. [CrossRef]

33. Bourgeat-Lami, E.; Lang, J. Encapsulation of inorganic particles by dispersion polymerization in polar media 1. Silica nanoparticles encapsulated by polystyrene. J. Colloid Interface Sci. 1998, 197, 293-308. [CrossRef]

34. Bartholome, C.; Beyou, E.; Bourgeat-Lami, E.; Chaumont, P.; Zydowicz, N. Nitroxide-Mediated Polymerizations from Silica Nanoparticle Surfaces: “Graft from" Polymerization of Styrene Using a Triethoxysilyl-Terminated Alkoxyamine Initiator. Macromolecules 2003, 36, 7946-7952. [CrossRef]

35. Guo, Z.X.; Yu, J. Grafting of dendritic polyethers onto nanometer silica surface. J. Mater. Chem. 2002, 12, 468-472. [CrossRef]

36. Kedong, X.; Lu, C.; Yang, Y.; Zhang, B. Effect of vinyltriethoxysilane addition on the pyrolytic conversion of tetraethoxysilane based silica gel. J. Sol-Gel Sci. 2014, 69, 266-271. 
37. Valdés, O.; Monett, D.; Agüero, L.; Zaldivar, D.; Alexandrova, L.; Katime, I. Synthesis and Characterization of Poly(acryloxyethyltrimethyl-ammonium chloride-co-2-hydroxyethyl methacrylate): A Study of its Interaction with Sodium Alginate. J. Appl. Polym. Sci. 2008, 108, 1680-1688. [CrossRef]

38. Valdés, O.; Alexandrova, L.; Zaldivar, D.; Katime, I. A comparative study of two polyelectrolyte complexes. J. Appl. Polym. Sci. 2012, 125, 3345-3350. [CrossRef] 